\title{
chaper Mental Hospitals, Social Exclusion and Public Scandals
}

\author{
Louise Hide
}

\section{Introduction}

On 10 November 1965, a letter appeared in The Times newspaper drawing readers' attention to the ill treatment of geriatric patients in certain mental hospitals. The authors, who included members of the House of Lords, the eminent academic Brian Abel-Smith, two senior clerics and the campaigner Barbara Robb, asked readers to send in evidence that would help them to make a case for a national investigation that could give the Ministry of Health more 'effective and humane' control over such hospitals. ' In response, hundreds of letters poured in. Many detailed appalling conditions and practices in 'geriatric' wards of psychiatric and general hospitals.

Two years later, towards the end of June 1967, a number of these accounts were published in Sans Everything: A Case to Answer. ${ }^{2}$ In July, a group of student nurses convened at Whittingham Hospital near Preston in Lancashire to voice their concerns regarding inhumane treatment on some wards. ${ }^{3}$ One month later, the News of the World newspaper exposed allegations of cruel practices and callous conditions which were subsequently revealed to have taken place at Ely Hospital in Cardiff. In late 1968, the police were called to investigate ill treatment of patients by male nurses at Farleigh Hospital in Somerset. While minor local inquiries were held into the allegations published in Sans Everything, broadly discrediting them, the inquiries into practices at Ely, Farleigh and Whittingham hospitals were the first in a long run of inquiries to be conducted into NHS psychiatric and 'mental handicap' hospitals, as they were then called, during the late 1960s and 1970s. They revealed a horrifying web of abuses, neglect, corruption and failures of care on certain wards - by no means all - and how they were facilitated by ingrained cultures that permeated socially, professionally and geographically isolated institutions.

This chapter provides an overview of the inquiries that took place into practices and conditions in some psychiatric and mental handicap hospitals, with a focus on the former. It describes the state of institutional care for people diagnosed with mental disorders in the post-war period and outlines the course this initial run of hospital 'scandals' took. It then examines why, when some ward cultures and hospital management practices had remained unchanged over decades, they were raised into public and political awareness at this particular point in time, bringing about changes in long-term care, particularly for older people in England and Wales.

\section{Mental Hospitals in the Post-war Period}

Following the Second World War, plans for the social reconstruction of the country, including a major reorganisation of health and social welfare systems, began to be 
implemented. Most hospitals were nationalised under the newly formed NHS and responsibility for them, including the large county mental and mental handicap hospitals, was passed from local governments to Regional Hospital Boards (RHBs) which were accountable to the Ministry of Health.

After the war, admissions into mental hospitals grew. By 1954, the rambling asylums of England and Wales contained around 154,000 people, ${ }^{4} 46$ per cent of whom had been resident for more than ten years, ${ }^{5}$ often living on overcrowded and under-resourced wards. When the psychiatrist David H. Clark joined Fulbourn Hospital in Cambridge in 1953, he described his first visit to the 'back' wards:

my conductor had to unlock every door; within the wards patients, grey-faced, clad in shapeless, ill-fitting clothes, stood still or moved about aimlessly ... [In the men's dormitories] ... chipped enamel chamber pots stood everywhere ... the smell of urine was strong and there were no personal items of any kind to be seen in the cold rooms ... there were no curtains on the windows ... the furniture was massive, deep brown, dingy and battered.

By contrast, the Admission Villas were described as 'sunlit, pleasantly decorated one-storey buildings with an air of brisk purpose' ${ }^{6}$

Interest in the symbiotic relationship between the environment, the body and the mind grew during the war. The 1946 Constitution of the World Health Organization (WHO) defined 'health' as 'a state of complete physical, mental and social well-being and not merely the absence of disease and infirmity. ${ }^{7}$ Theories around the psychosocial stirred the interest of sociologists and social psychiatrists into the effects of institutional environments on those who lived and worked inside them. Hospitals, including mental hospitals, were run along ingrained militaristic lines which were imposed on both staff and patients as a form of managing and controlling large numbers of people who might be mentally unwell. A strict routine was enforced from the moment patients got up in the morning until going to bed at night, which could be as early as 5 p.m. Personal possessions were often 'removed' on admission, clothing was shared, staff wore uniforms and doctors were referred to as medical 'officers'. Hierarchies were strict. Eric Pryor, who joined Claybury Hospital as a student nurse soon after the end of the war, explained how 'there was no fraternising, either with those above or below one's own rank ... It was not etiquette for junior staff to speak to Medical Staff, Head Nurses or official visitors unless spoken to.'

In Britain, the concept of 'institutionalisation' emerged into clinical discourse from the 1950s. The deputy physician superintendent at Claybury, Denis V. Martin, remarked in 1955 that terms such as 'becoming institutionalised' or 'well institutionalised' could often be found in clinical notes, meaning that a patient had 'more or less' surrendered to institutional life and was seen by nurses as 'resigned', 'cooperative' and not causing any trouble. The more institutionalised patients became, the more manageable and tractable their behaviour. In Martin's view, some doctors, who might be responsible for up to 300 patients, had a 'vested interest in maintaining the process of institutionalization' because it gave them more time to focus on the patients they found more therapeutically interesting. Yet it was nurses who managed the day-to-day lives of patients and 'ran' the wards. Martin argued that their training 'far more than the doctors' is destructive of individuality'.

Russell Barton, a social psychiatrist and medical superintendent of Severalls Hospital in Essex, suggested that the institution was in itself pathogenic. Patients suffered from two conditions: one for which they were initially admitted and a second caused by the stultifying environment of the hospital resulting in a condition that was 'characterized by apathy, lack 
of initiative, loss of interest ... [and] submissiveness'. ${ }^{10}$ Perhaps the best-known indictment of the large institutions was Asylums (1961) by the Canadian sociologist Erving Goffman. Based on his study of a large mental hospital in Washington, DC, it was an excoriating critique of psychiatric hospitals and their effects on patients. Asylums were, according to Goffman, 'total institutions' which he defined as places of 'residence and work where a large number of like-situated individuals, cut off from the wider society for an appreciable period of time, together lead an enclosed, formally administered round of life. ${ }^{11}$

Steps were taken to improve institutional life. During the war, a group of doctors, some of whom had been trained in psychotherapy, created more open and egalitarian therapeutic communities to help rehabilitate servicemen. Some of these approaches were subsequently adopted by social psychiatrists such as Clark and Martin to help patients regain a sense of independence and leave hospital. The large mental hospitals began to move away from the old custodial practices and follow guidance from the WHO which stated that the life within the hospital should, as far as possible, be modelled on life within the community in which it is set'. ${ }^{12}$ Doors were unlocked and spaces were liberalised so that patients could move freely around the buildings and grounds. More therapeutic ward practices based on less rigid hierarchies and routines - nurses no longer wore uniforms and might be called by their first names - were introduced to help patients learn how to live more independently. These measures were bolstered from the mid-1950s by the introduction of new psychotropic drugs, such as chlorpromazine, which could alleviate severe psychotic symptoms. With the right medication and access to treatments such as electroconvulsive therapy (ECT) available in outpatient clinics, hospitalisation was no longer deemed necessary for many people experiencing serious mental health conditions.

New treatments, both biological and psychosocial, were matched by a strengthening political resolve to close the old asylums. In 1961, the Conservative minister of health, Enoch Powell, gave his 'water-tower' speech articulating the government's intention to reduce the number of psychiatric beds by half and to close the large isolated mental hospitals. The 1962 Hospital Plan mapped out how treatment would shift to psychiatric wards in district general hospitals. ${ }^{13}$ It also signalled formally the beginning of the deinstitutionalisation process and the move towards care in the community (see also Chapter 31).

\section{Two Standards of Care}

Psychiatry's new therapeutic approach was not primarily intended for older, long-term patients who were believed to be suffering from incurable conditions, such as senile dementia, about which nothing could be done. When it came to distributing resources, services for younger people with acute conditions were prioritised over those for people with long-term chronic conditions, creating a two-tier system. Whittingham Hospital, which was the subject of a major inquiry in the early 1970s, is a good case in point. Located in an isolated spot some seven miles outside of Preston in Lancashire, it was a large sprawling institution that had been established in 1873. Some of the buildings had been modernised but the majority were described by the inquiry report as the old 'threedecker wards of 80 beds or more, with large cheerless day-rooms and grossly inadequate sanitary facilities'. In accordance with the government's plan to close the asylums, Whittingham was to be gradually run down until it could be closed. To that end, the number of occupied beds dropped from 3,200 in 1953 to slightly more than 2,000 in 1969. ${ }^{14}$ This reduction was achieved through more 'active' psychiatry, when people with 
'treatable' conditions were moved from Whittingham to acute psychiatric units. As a result, 86 per cent of inpatients who remained at Whittingham had been in the hospital for longer than two years and a high proportion were old. ${ }^{15}$ The chairman of Whittingham's Hospital Management Committee - who was severely criticised in the inquiry - described this group of patients as 'the type who sit around all day just doing nothing but becoming cabbages'. ${ }^{16}$

\section{The 'Scandals'}

The depressing environment on some of Whittingham's long-stay wards was not uncommon. Early in 1965, Barbara Robb visited an acquaintance who had been admitted to Friern Hospital in North London. She was horrified by the dismal ward conditions and later described how older female patients in some hospitals were deprived of 'their spectacles, dentures, hearing aids and other civilized necessities' and left 'to vegetate in utter loneliness and idleness'. ${ }^{17}$ Within months, Robb established the pressure group AEGIS (Aid for the Elderly in Government Institutions). ${ }^{18}$

Robb was a co-signatory of the letter to The Times mentioned in the Introduction to this chapter. In 1967, two years after its publication, she presented on behalf of AEGIS a book titled Sans Everything: A Case to Answer which included carefully chosen accounts that had been sent in by nurses and social workers describing heartbreaking cruelty, neglect and suffering on geriatric wards. The book caused a public outcry. The Labour minister of health, Kenneth Robinson, who had ignored Robb's earlier requests to investigate conditions at Friern, ordered the relevant RHBs to investigate the allegations relating to the hospitals in their region. The results of the inquiries were published in a single report. ${ }^{19}$ Many of the original allegations were strenuously refuted and described as 'false', 'incomplete and distorted'; one informant was described as a 'highly emotional witness, prone to gross exaggeration'. ${ }^{20}$

Running simultaneously to the publication of Sans Everything was the exposure (without naming the hospital or individuals concerned) by the News of the World in August 1967 of allegations of patient mistreatment, failures of care and staff 'pilfering' at Ely Hospital in Cardiff, a former Poor Law institution primarily for 'sub-normal' or 'severely sub-normal' patients (see also Chapter 24). A delegation from the Ministry of Health had inspected Ely two years earlier when members had found appalling conditions yet done nothing to address them. ${ }^{21}$ Worried about public criticism, the minister instructed the RHB to establish an inquiry into Ely, which was to be led by Geoffrey Howe QC. ${ }^{22}$ The way in which the inquiry was set up - the structure of the committee and the terms of reference - was similar to the methods used to investigate the Sans Everything allegations. Howe did, however, extend the investigations beyond the events that took place to expose broader structural failings, including weak medical leadership, poor standards of nursing and an inadequate Hospital Management Committee. ${ }^{23}$

On 18 July 1967, just after the publication of Sans Everything, a meeting was convened at Whittingham Hospital by the Student Nurses Association which gathered to make a number of serious allegations of inhumane, cruel and even violent treatment of vulnerable older people on certain long-stay wards. Their complaints were consistently suppressed and ignored by the hospital. Two years later, a psychiatrist and a psychologist wrote directly to the Secretary of State alleging 'ill-treatment of patients, fraud and maladministration, including suppression of complaints from student nurses'. An inquiry was launched when allegations of ill treatment were concentrated on four long-stay wards, one of which had been run by the same Sister for forty-seven years. ${ }^{24}$ 
At Farleigh Hospital in Bristol, concerns about serious mistreatment and violence towards patients emerged at the end of 1968 when the police were called to investigate brutal treatment by male nurses of men with severe mental handicaps. Following judicial proceedings, when three of the nine nurses who had been charged received prison sentences, an inquiry was launched into the administrative systems and conditions of the hospital in order to understand the cultural and systemic mechanisms that had facilitated abuses of care over such a long period of time.

Claire Hilton has rightly argued that it was the publication of Sans Everything and the tireless work of Barbara Robb, among others, that triggered widespread revelations of abuses leading to Ely, which was the first inquiry into NHS care to be published in full. ${ }^{25}$ The Whittingham Hospital Inquiry (1972) was also significant because, according to the sociologist John Martin, it 'dissected the organization which had allowed maltreatment and pilfering to occur, and which had stubbornly resisted all attempts to change old styles of care'. A socially and professionally isolated environment had been a major factor in allowing practices and customs to persist. ${ }^{26}$ At least ten inquiries of national significance, and many other smaller ones, were conducted from the late 1960s and throughout the 1970s. ${ }^{27}$

Given that 'care' on long-term geriatric wards had often been so wretched for so long, and that so many knew about it, why did no one act before and how were such practices allowed to continue ${ }^{28}$ Sociologists Ian Butler and Mark Drakeford have argued that the 'everyday tragedies' that were revealed by the welfare scandals of the 1960s and 1970s are 'where meanings and historical significance become attached to acts and events that at other times might have passed almost unobserved'. ${ }^{29}$ Widespread social change was in process, driven in part by human and civil rights campaigns, counterculture movements which challenged the prevailing establishment, including psychiatry (see Chapter 13 and 14), and service-user pressure groups like Mind which demanded greater rights for patients. ${ }^{30}$ The isolated and dilapidated former asylums that housed ossified professional and social cultures were anachronistic and belonged to the past. They had to go.

The media played a crucial part in raising public awareness which, in turn, put pressure on the government to act. In addition to the News of the World, which had supported AEGIS and Sans Everything, ${ }^{31}$ and broken the Ely story, The Lancashire Evening Post set up a 'press desk' in a local pub to gather information about malpractices at Whittingham Hospital before publishing 'A Big Probe into Allegations of Cruelty' in February 1970. ${ }^{32}$ Television took the horrors of overcrowded wards and inhumane treatment into people's living rooms. In 1968, World in Action broadcast Ward F13, showing the harrowing conditions in which women were living on a female geriatric ward in Powick Hospital in Worcestershire, while younger patients with acute conditions were being treated in well-resourced facilities in the same hospital. In this case, it was the medical superintendent who had invited the cameras into the hospital so that viewers could see for themselves the inequities of the two-tier system. $^{33}$

\section{Change}

As one inquiry after another was held during the 1970s, a pattern of underlying causes that could be attributed to such catastrophic failures of care began to emerge. They included geographical, social and professional isolation; patients with no one to advocate for them; an absence of formal complaints procedures; the privileging of task-centred nursing or other professional interests over the needs of patients; failures of leadership; poor administration 
and lay management; union intervention; inadequate training; and personal failings. ${ }^{34}$ Threaded through these factors were deeply ingrained values and belief systems which had been passed on for years; these included ageism and the commonly held belief that older patients were suffering from inevitable and untreatable cognitive decline, which in many cases was erroneous (see also Chapter 22).

In 1969, the Labour MP Richard Crossman, who had replaced Kenneth Robinson and become the secretary of state for the newly formed Department of Health and Social Services, took over responsibility for hospitals providing long-term care. Crossman had a strong personal and professional interest in bringing about reform and quickly established an independent inspectorate, the Hospital Advisory Service, which was to evaluate and regulate long-stay hospitals. ${ }^{35}$ An NHS ombudsman with a remit to introduce an effective complaints process was introduced in $1972 .{ }^{36}$ While patient numbers fell, the government allocated more resources to long-stay hospitals. During the 1970s, medical and nursing staff levels rose in both psychiatric and mental handicap hospitals. Conditions were improved and there was some diversification into various sub-specialisms including psychogeriatric medicine. ${ }^{37}$ Three important White Papers were produced by the DHSS: Better Services for the Mentally Handicapped (1971), Services for Mental Illness Related to Old Age (1972) and Better Services for the Mentally Ill (1975). The latter framed mental illness as a social as well as a medical issue and set out plans to improve the provision of community care through expanding local authority social services and to move away from institutional care. ${ }^{38}$ This process took a decisive turn when a new Conservative government led by Margaret Thatcher came into power in 1979 and opened the provision of care to private, voluntary and independent sectors - often in large houses that were not fit for purpose. The old asylums began to close in the 1980s and valuable sites and buildings were sold, reducing the number of available hospital beds. When local authorities failed to provide suitable accommodation in the community, people who had left hospital were faced with the prospect of having nowhere to go.

\section{Conclusion}

This chapter has examined the ways in which 'exclusion' as a social mechanism allowed appalling conditions and practices to persist in mental hospitals over many years, leading to inquiries into the failures of long-term NHS care and subsequent scandals. Geographical remoteness led to professional exclusion as hospitals became increasingly inward-looking and medical and nursing staff lost touch with developments in their respective fields. The inquiries were an important catalyst that helped bring about the closure of the old asylums, many of which had played a central role in the segregation of people who were believed to be mentally unwell or socially 'undesirable' from society. The two-tier system had been active since the late nineteenth century. Embedding it into policy through deinstitutionalisation, from the early 1960s, imposed an additional layer of exclusion upon those who were left behind on the 'back' wards. Those who did leave the institutions could find themselves facing new forms of isolation as facilities in the community could fail to materialise or to provide adequate care.

While long-term care is now provided in smaller, usually privately owned, facilities, abuse, undignified treatment and neglect continue to be seen but unseen, known but unknown. Inquiries may be expensive and repetitive. They may need to be reimagined and reframed to engage with different questions and perspectives. Whatever their shortcomings, they remain 
vital mechanisms for uncovering harmful practices visited on vulnerable people. They can reassure the public and, crucially, highlight where changes need to be made by individuals and professional groups, as well as by management and policymakers.

\section{Key Summary Points}

- Between the late 1960 s and early 1980 s, at least ten major and many smaller inquiries were held into neglectful, abusive and violent practices in psychiatric and 'mental handicap' hospitals.

- Many institutions, or certain wards inside them, had become professionally isolated and severely under-resourced. Deeply ingrained cultures of harm and neglect had evolved over years.

- Growing interest in the effects of institutional environments on patients contributed to the post-war impetus to move care for acute conditions into the community, leaving long-stay wards more isolated than ever.

- The exposure of harmful practices by the press and campaigners compelled politicians to order inquiries which contributed to changes in the provision of long-term care and the widespread closure of the old Victorian asylums from the 1980s.

- While long-term care is now provided in smaller facilities, abuse, undignified treatment and neglect continue. Inquiries may need to be reimagined and reframed to engage with different questions and perspectives.

\section{Acknowledgements}

My thanks to Claire Hilton for her helpful comments.

\section{Notes}

1. Strabolgi et al., The Times, 10 November 1965; 13.

2. B. Robb, Sans Everything: A Case to Answer. London: Thomas Nelson, 1967. This was compiled on behalf of AEGIS.

3. NHS, Report of the Committee of Inquiry into Whittingham Hospital, Cmnd. 4861. London: HMSO, 1972.

4. H. Freeman, Psychiatry and the state in Britain. In M. Gijswijt-Hofstra, H. Oosterhuis, J. Vijselaar and H. Freeman, eds, Psychiatric Cultures Compared: Psychiatric and Mental Health Care in the Twentieth Century: Comparisons and Approaches, 116-40. Amsterdam: Amsterdam University Press, 2005.

5. J. Turner, R. Hayward, K. Angel et al., The history of mental health services in modern England: Practitioner memories and the direction of future research. Medical History (2015) 59(4): 599-624.

6. D. H. Clark, The Story of a Mental Hospital: Fulbourn 1858-1983. London: Process Press, 1996, pp. 1-2.

7. World Health Organization (WHO), Constitution of the World Health Organization. New York, 22 July 1946. https://apps.who.int/gb/bd/PDF/bd48/basic-documents-48th-edition-en.pdf.

8. E. H. Pryor, Claybury 1893-1993: A Century of Caring. London: The Mental Health Care Group, 1993 , p. 106.

9. D. V. Martin, Institutionalisation. The Lancet (1955) 269: 1188-90.

10. R. Barton, Institutional Neurosis (3rd ed.). Bristol: John Wright \& Sons, 1976, p. 2. (Originally published in 1959.)

11. E. Goffman, Asylums: Essays on the Social Situation of Mental Patients and Other Inmates. London: Penguin, 1991, p. 11. (Originally published in 1961.) 
12. WHO, The Community Mental Hospital: Third Report of the Expert Committee on Mental Health. Geneva: WHO, 1953, p. 19.

13. Freeman, Psychiatry and the state in Britain.

14. NHS, Report of the Committee of Inquiry into Whittingham Hospital.

15. J. P. Martin and Debbie Evans, Hospitals in Trouble. Oxford: Basil Blackwell, 1984.

16. NHS, Report of the Committee of Inquiry into Whittingham Hospital; 5-6.

17. Robb, Sans Everything, p. xiii.

18. C. Hilton, Improving Psychiatric Care for Older People: Barbara Robb's Campaign 1965-1976. Cham: Palgrave Macmillan, 2017.

19. For a more detailed account of this process, see C. Hilton, A tale of two inquiries: Sans Everything and Ely. The Political Quarterly (2019) 90(2): 185-93.

20. NHS, Findings and Recommendations Following Enquiries into Allegations Concerning the Care of Elderly Patients in Certain Hospitals, Cmnd 3687. London: HMSO, 1968, pp. 23, 68, 36, 24, 82.

21. Hilton, A tale of two inquiries.

22. Howe later became Margaret Thatcher's longest-serving Cabinet minister, holding the posts of Chancellor of the Exchequer, Foreign Secretary and, finally, Leader of the House of Commons, Deputy Prime Minister and Lord President of the Council.

23. Martin, Hospitals in Trouble.

24. NHS, Report of the Committee of Inquiry into Whittingham Hospital, pp. 1, 11.

25. Hilton, A tale of two inquiries.

26. Martin, Hospitals in Trouble, pp. 9, 17.

27. Ibid., p. xi. In addition to Ely, Farleigh and Whittingham, similar major inquiries were held into Napsbury Hospital (1973), South Ockendon Hospital (1974) and Normansfield Hospital (1978). Dates relate to the publication of reports.

28. N. Stanley and J. Manthorpe, Introduction: The inquiry as Janus. In N. Stanley and J. Manthorpe, eds, The Age of the Inquiry: Learning and Blaming in Health and Social Care. London: Routledge, 2004.

29. I. Butler and M. Drakeford, Scandal, Social Policy and Social Welfare. Basingstoke: Palgrave Macmillan, 2005, p. 1.

30. Turner, Hayward, Angel et al., The history of mental health services in modern England.

31. Hilton, Improving Psychiatric Care for Older People.

32. Butler and Drakeford, Scandal, Social Policy and Social Welfare, p. 118.

33. Granada Television, Ward F13, World in Action broadcast, 1968.

34. Martin, Hospitals in Trouble, chap. 5.

35. P. Bridgen, Hospitals, geriatric medicine, and the long-term care of elderly people 1946-1976. Social History of Medicine (2001) 14(3): 507-23.

36. Hilton, Improving Psychiatric Care for Older People.

37. Turner, Hayward, Angel et al., The history of mental health services in modern England; Freeman, Psychiatry and the state in Britain.

38. The Health Foundation, “Better services for the mentally ill” white paper'. The Health Foundation website, https://navigator.health.org.uk/theme/better-services-mentally-ill-white-paper. 
